\title{
The Long Pentraxin PTX3 as a Link Between Innate Immunity, Tissue Remodeling, and Cancer
}

\author{
Andrea Doni ${ }^{1}$, Matteo Stravalaci ${ }^{2}$, Antonio Inforzato ${ }^{1,2}$, Elena Magrini ${ }^{1}$, \\ Alberto Mantovani ${ }^{1,2,3}$, Cecilia Garlanda ${ }^{1,2 *}$ and Barbara Bottazzi ${ }^{\text {1* }}$ \\ ${ }^{1}$ Humanitas Clinical and Research Institute-IRCCS, Milan, Italy, ${ }^{2}$ Department of Biomedical Sciences, Humanitas University, \\ Milan, Italy, ${ }^{3}$ The William Harvey Research Institute, Queen Mary University of London, London, United Kingdom
}

OPEN ACCESS

Edited by:

Massimo Gadina,

National Institute of Arthritis and Musculoskeletal and Skin Diseases

(NIAMS), United States

Reviewed by:

Darrell Pilling,

Texas A\&M University, United States

Marco Presta

University of Brescia, Italy

*Correspondence:

Cecilia Garlanda

cecilia.garlanda@humanitasresearch.it

Barbara Bottazz

barbara.bottazzi@humanitasresearch.it

Specialty section:

This article was submitted to

Inflammation,

a section of the journal

Frontiers in Immunology

Received: 10 January 2019

Accepted: 15 March 2019

Published: 04 April 2019

Citation:

Doni A, Stravalaci M, Inforzato A, Magrini E, Mantovani A, Garlanda C and Bottazzi B (2019) The Long Pentraxin PTX3 as a Link Between Innate Immunity, Tissue Remodeling, and Cancer. Front. Immunol. 10:712.

doi: 10.3389/fimmu.2019.00712
The innate immune system comprises a cellular and a humoral arm. Humoral pattern recognition molecules include complement components, collectins, ficolins, and pentraxins. These molecules are involved in innate immune responses by recognizing microbial moieties and damaged tissues, activating complement, exerting opsonic activity and facilitating phagocytosis, and regulating inflammation. The long pentraxin PTX3 is a prototypic humoral pattern recognition molecule that, in addition to providing defense against infectious agents, plays several functions in tissue repair and regulation of cancer-related inflammation. Characterization of the PTX3 molecular structure and biochemical properties, and insights into its interactome and multiple roles in tissue damage and remodeling support the view that microbial and matrix recognition are evolutionarily conserved functions of humoral innate immunity molecules.

Keywords: pentraxins, PTX3, inflammation, tissue remodeling, wound healing

\section{INTRODUCTION}

Innate immune responses are the first strategies of host defense from invading pathogens and tissue damage. Their activation occurs when conserved structures on the surface of pathogens or associated with tissue damage, called pathogen associated molecular patterns (PAMPs) and damage-associated molecular patterns (DAMPs), respectively, are recognized by cell-associated or soluble molecules known as pattern recognition molecules (PRMs). Among soluble PRMs, pentraxins are a superfamily of evolutionarily conserved molecules with multi-functional roles in innate immunity and inflammation, such as regulation of complement activation and opsonization of pathogens (1). C-reactive protein (CRP) and serum amyloid P component (SAP) are the short or "classical" pentraxins. CRP is mainly produced by hepatocytes as an acute phase protein in man as well as other mammalian species, but not in mouse, in response to interleukin (IL)-6, whereas SAP is the short pentraxin acting as an acute phase protein in mouse (2). Pentraxin 3 (PTX3) is the prototype of the long pentraxin subfamily, originally identified as an IL-1 or TNFinducible gene. PTX3 is produced by different cell types in response to primary pro-inflammatory stimuli and microbial moieties, is an essential mediator of innate resistance to selected pathogens of fungal, bacterial and viral origin [as discussed elsewhere $(1,3)$ ], and is involved in regulation of inflammation, tissue remodeling, and cancer. 
Here we will review the main biological features of PTX3 focusing on its structure and involvement in sterile conditions of tissue damage and cancer, and providing evidence that microbial and matrix recognition are evolutionarily conserved properties shared by humoral innate immunity molecules.

\section{GENE REGULATION AND PROTEIN STRUCTURE}

The human and the murine PTX3 gene map on chromosome 3 and are organized in three exons, the first two coding for the leader peptide and the N-terminal domain, and the third coding for the C-terminal-pentraxin domain (Figure 1).

PTX3 is mainly induced by pro-inflammatory cytokines, such as IL- $1 \beta$ and TNF $\alpha$, and by TLR agonists, microbial components (e.g., LPS, lipoarabinomannan, and outer membrane proteins of selected Gram-negative bacteria), and intact microorganisms (Figure 1). PTX3 expression is inducible in a wide variety of cell types, including fibroblasts and endothelial cells, myeloid cells such monocytes, macrophages, and dendritic cells (DCs), synovial cells, chondrocytes, adipocytes, glial and mesangial cells, epithelial cells and retinal cells (1, 4, 5) (Figure 1). High density and oxidized low density lipoproteins (HDL and ox-LDL) induce PTX3 production in endothelial cells and primary vascular smooth muscle cells (SMC) $(6,7)$.
Microbial ligands stimulate the release of PTX3 from neutrophils, where the protein, mostly produced by myeloid precursors, is constitutively stored in specific granules $(8,9)$. Among peripheral blood mononuclear cells, only monocytes exposed to inflammatory cytokines or LPS produce PTX3 mRNA (1). PTX3 expression is negatively regulated by IFN- $\gamma$, IL-4, dexamethasone, $1 \alpha, 25$-dihydroxivitamin D3, and prostaglandin E2 $(5,10,11)$. PTX3 is also induced by ovulatory stimuli in granulosa cells, and when released it contributes to the structural architecture of cumulus oophorus extracellular matrix (12).

PTX3 expression and production is regulated by different signaling pathways, mainly depending on the cell type and/ or stimuli. The NF-кB pathway controls PTX3 expression in conditions of IL-1 receptor- or TLR-dependent inflammation (13-15), while induction of the protein by $\mathrm{TNF} \alpha$ in lung epithelial cells involves the c-Jun N-terminal kinase (JNK) pathway (16). HDL-induced PTX3 production in endothelial cells requires the activation of the PI3K/Akt pathway through G-coupled lysosphingolipid receptors (7).

The expression of the human PTX3 gene in physiological and inflammatory conditions is also regulated by epigenetic mechanisms. Hypermethylation of the promoter region and of an enhancer encompassing the second PTX3 exon (enhancer 2) (Figure 2) have been associated with PTX3 gene silencing in selected human tumors (e.g., colon rectal cancer and

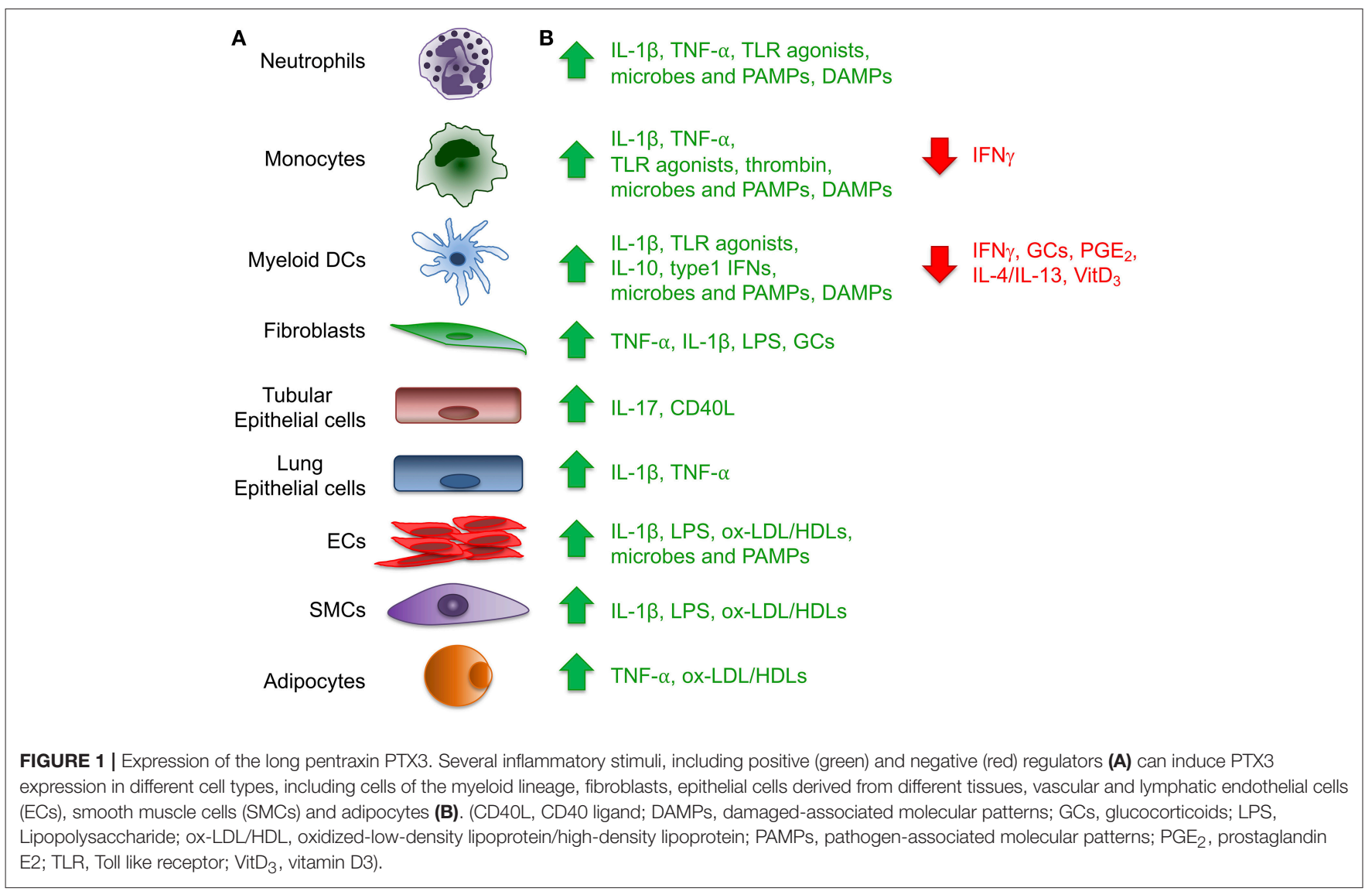




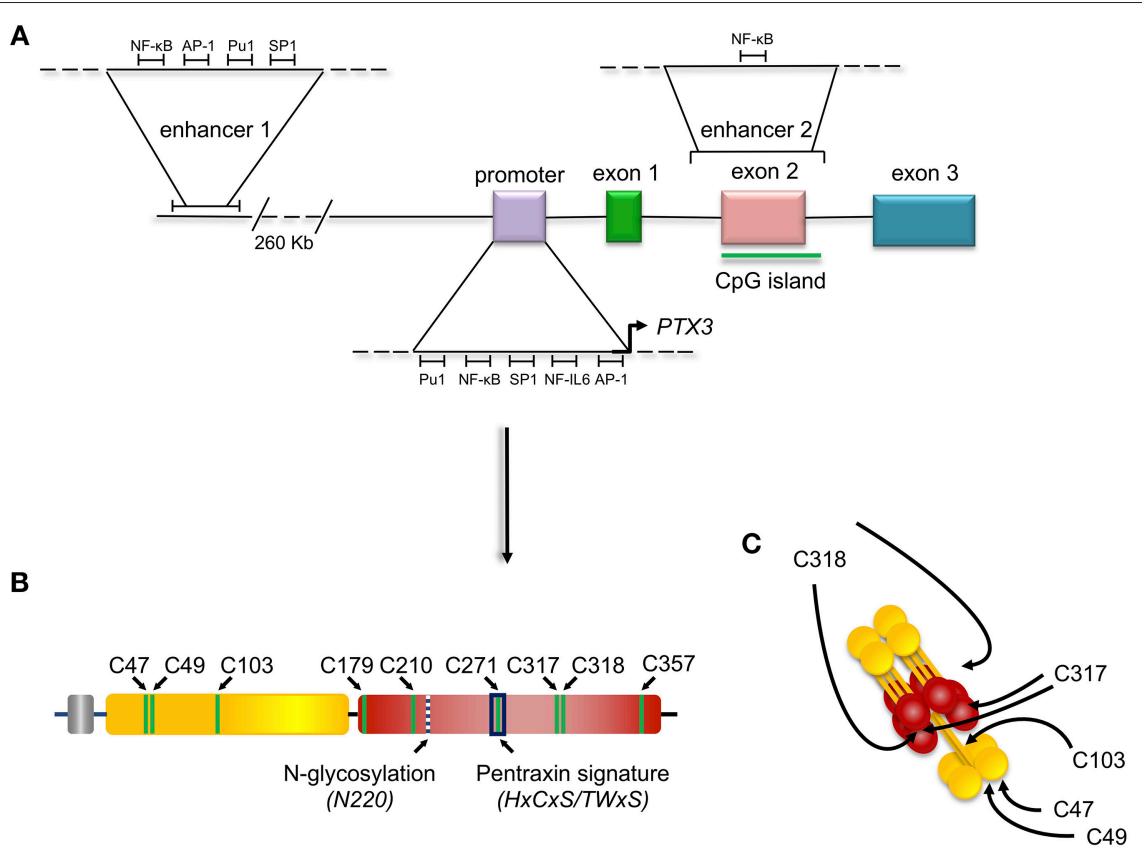

FIGURE 2 | Gene and protein structure of the long pentraxin PTX3. PTX3 gene is located in chromosome 3 and is organized in three exons: the first coding for the signal peptide, the second coding for the N-terminal domain, and the third coding for the C-terminal, pentraxin domain. The promoter of PTX3 contains several transcription factor binding sites, including Pu1, NF-kB, SP1, NF-IL6, and AP-1. Depicted are also the sites of PTX3 epigenetic regulation, mediated by two potentially active enhancers. The first enhancer-containing the transcription factor binding sites for NF-kB, AP-1, Pu1, and SP1 - is located $230 \mathrm{~kb}$ upstream of the promoter, while the second enhancer-containing the transcription factor binding site for NF-kB-encompasses the second PTX3 exon (A). Schematic representation of the PTX3 protomer subunit with the leader peptide in gray, the $\mathrm{N}$-terminal region in yellow, and the pentraxin C-terminal domain in red. Shown are the Cys residues involved in intra- (C179-C357, and C210-C271) and inter- (C47-C47, C49-C49, C103-C103, C317/318-C317/318) chain disulfide bonds, the N-glycosylation site at Asn220, and the pentraxin signature (a primary sequence motif highly conserved across pentraxins) (B). 8 protomer subunits assemble into an octameric protein stabilized by inter-chain disulfides (as well as non-covalent interactions), which are pointed to by arrows in the picture (C).

leiomyosarcoma) (14). Consistent with this, hypomethylation of these regulatory elements correlated with higher than normal protein levels in the plasma of coronary artery disease patients (17). Recent studies have characterized these epigenetic mechanisms in the context of different PTX3 expressing cells, including macrophages and fibroblasts, and have further addressed the epigenetic modifications occurring in the PTX3 gene in colorectal cancer (CRC) (18). These investigations identified a second enhancer located $230 \mathrm{~kb}$ upstream of the PTX3 gene promoter (enhancer 1, Figure 2). In silico and ChIP analysis revealed the binding of several transcription factors on this enhancer (18). Many of them, including the NF- $\kappa B$ subunit RelA, c-Jun, c-Fos, PU.1, and SP.1, are involved in the activation of inflammatory and immune responses, and are also known to control the activity of PTX3 promoter (Figure 2). The enhancer 2 was found only to bind NF-кB after TNF$\alpha$ stimulation in macrophages, suggesting that this regulatory element could be important in the activation of tissue-specific transcription factors. However, the enhancer 2 could have a direct role in activating the expression of PTX3, since ChIP analysis showed its interaction with TAF1, a member of the transcription preinitiation complex (PIC) (18). Furthermore, STAT3-mediated hypermethylation of enhancer 1 has been associated with PTX3 gene silencing in colorectal cancers (18)
(Figure 2). Interestingly, in vitro treatment of macrophages with glucocorticoid hormones, such as dexamethasone, results in M2 polarization, which is associated with immune suppression, and tumor progression (19). Noteworthy, one of the main markers of this phenotype is activation of STAT3, thus suggesting that STAT3-mediated PTX3 downregulation could be involved in carcinogenesis (see below).

Amongst PTX3 single nucleotide polymorphisms (SNPs), three (collectively forming an haplotypic block) have been found associated with susceptibility to infections including those caused by Aspergillus fumigatus (20-23), Mycobacterium tuberculosis (24), and Pseudomonas aeruginosa (25). Two of these SNPs are located in PTX3 intronic non-coding regions (rs2305619 in intron 1, and rs1840680 in intron 2), while the third is an exonic polymorphism that causes an amino acid substitution at position 48 (D48A, or rs3816527). Epidemiological studies have found a correlation between these three SNPs and PTX3 plasma levels, however the molecular mechanisms responsible for this association are still poorly understood. In this regard, individuals carrying the D48 allele have lower systemic concentrations of PTX3 (26). This might be due to faster rate of mRNA degradation, as proposed by Cunha et al. (20), or, alternatively, reduced activity of the second enhancer in the PTX3 gene (that encompasses the rs2305619, rs3816527, and rs1840680 SNPs) 
(18). It is not currently possible to exclude a direct local effect of amino acid substitution on protein structure (therefore function).

PTX3 is a multimeric glycoprotein whose protomer subunits comprise 381 amino acids. The protein primary sequence is highly conserved in evolution (with $82 \%$ identity between human and murine PTX3), likely due to early selection and enduring maintenance in phylogenesis of fundamental structure/function relationships. Analogous to other members of the long pentraxin sub-family, which includes guinea pig apexin, rat, human, and murine neuronal pentraxins 1 (NP1, or NPTX1) and 2 (NP2, also known as Narp or NPTX2), the putative integral membrane pentraxin NRP, and PTX4 (27), the PTX3 protomer is organized into an N-terminal region and a 203 amino acids long Cterminal domain with homology to the short pentraxins CRP and SAP (28) (Figure 2).

The N-terminal domain has no obvious similarity to any protein of known structure. However, secondary structure predictions indicate that this domain mostly comprises $\alpha$-helical elements, three of which are likely organized into coiled-coils (6). Furthermore, the N-terminal end of this domain (amino acids 18-54) is predicted to be intrinsically disordered, a property that might provide the PTX3 protein with structural and functional versatility (29), thus contributing to the remarkable complexity of its interaction network (3).

The C-terminal domain shares with the short pentraxins a considerable degree of homology (with up to 57\% similarity), which has allowed generation of 3D models based on the crystal structures of CRP (PDBID:1b09) and SAP (PDBID:1sac) (3032) indicating that it adopts a $\beta$-jelly roll topology, stabilized by two intra-chain disulfide bonds (33). Two additional cysteine residues (i.e., Cys317 and Cys318) are involved both in intra- and inter-chain disulfides that, in conjunction with inter-chain bonds made by cysteine residues of the N-terminal domain, support the quaternary structure of the mature PTX3 protein (34) (Figure 2).

The pentraxin domain of PTX3 bears a single N-glycosylation site at Asn220 that, in a recombinant form of the protein from $\mathrm{CHO}$ cells, is fully occupied by complex type oligosaccharides, mainly fucosylated and sialylated biantennary sugars with a minor fraction of tri-and tetraantennary glycans. N-linked complex type glycosylation occurs in the natural protein made by human cells too (32), and mediates some of the PTX3 biological functions, including inhibition of influenza A virus hemagglutination $(35,36)$ and recognition of P-selectin (37). Furthermore, protein glycosylation (with major regard to sialylation) modulates the interaction of PTX3 with C1q, and the regulatory effect of PTX3 on complement activation via the classical pathway (32). We speculate that the molecular crosstalk between PTX3 and a range of diverse ligands involves a common glycan code, whereby tissue- and microenvironment-specific changes in the protein glycosylation profile might regulate its biological properties [see (38) for a review].

The modular (i.e., $\mathrm{N}$ - and C-domains) and sub-modular (i.e., coiled-coils and intrinsically disordered regions of the $\mathrm{N}$-domain) nature of the protomer likely endows PTX3 with the structural versatility that is required to support its diverse interactions, thereby its biological functions. In this regard, the $\mathrm{N}$-terminal region of the protein contains binding sites for fibroblast growth factor 2 (FGF2), inter- $\alpha$-inhibitor (I $\alpha$ I), TNF$\alpha$-induced protein 6 (TNFAIP6 or TSG-6), plasminogen (Plg), fibrin, and conidia of A. fumigatus (15, 39-42). C1q and Pselectin mostly interact with the pentraxin-like domain $(28,37)$, whereas both domains have been implicated in the recognition of complement factor $\mathrm{H}(43,44)$, and Ficolin-1 (45).

In addition to the multidomain organization, PTX3 has a complex quaternary structure with high-order oligomers stabilized by disulfide bonds. Mass spectrometry and sitedirected mutagenesis indicate that PTX3 is made of covalent octamers (i.e., with a molecular mass of $340 \mathrm{kDa}$ ), through inter-chain disulfides bridges (34) (Figure 2). A low-resolution model based on data from electron microscopy and small angle X-ray scattering shows that eight PTX3 protomers fold into an elongated molecule with two differently sized domains interconnected by a stalk region, and a pseudo 4 fold symmetry along the longitudinal axis (33). Such quaternary structure is unique among pentraxins, where CRP and SAP both share a prototypical pentameric planar symmetry $(46,47)$. The only other pentraxin that forms an octamer is SAP from Limulus polyphemus, which, however, folds into a doubly stacked octameric ring (48). In addition, the oligomeric organization has important implications in its ligand binding properties. For example, the PTX3 octamer contains two binding sites for FGF2, and tetrameric recombinant forms of the N-terminal domain recapitulate the inhibitory functions of the full length protein toward this factor both in angiogenesis $(33,39)$ and bone deposition (49). However, dimeric forms of the N-terminal domain retain binding to I $\alpha$ I and TSG-6, thereby the octameric PTX3 protein is likely endowed with multiple (at least four) binding sites for each of these ligands, and can act as a nodal molecule in cross-linking hyaluronic acid in the extracellular matrix $(41,50)$.

High resolution models are urgently needed to disentangle the structural complexity of this long pentraxin and shed light on its structure/function relationships, some of which are remarkably different to those classically described for the short pentraxins.

\section{ROLE OF PTX3 IN TISSUE REPAIR}

Beyond its role as the first line of resistance against pathogens, innate immunity is involved in initiating the process of tissue repair (51-53). The cellular arm of the innate immune system senses specific DAMPs and regulates inflammatory responses at sites of damage $(52,54)$. The humoral arm of the innate immunity has different and complex roles ranging from the clearance of apoptotic cells and regulation of immune cell migration and activation, to regulation of remodeling cell activity $(55,56)$. For instance, SAP regulates fibrosis by inhibiting the alternative activation of macrophages via FcyRs (57) or by modulating immune cell activities via DC-SIGN (58). Pentraxins and components of the complement system also interact with elements present in the extracellular matrix (ECM), thus suggesting additional regulatory roles of the innate immune system in the tissue response to injury $(53,59)$. On the other hand, different ECM components, such as fibronectin, 
TABLE 1 | Biological functions of PTX3 in tissue remodeling and cancer.

\begin{tabular}{|c|c|c|c|}
\hline & & Ligands & Functions \\
\hline \multirow[t]{5}{*}{ Tissue remodeling } & Fertility & $\begin{array}{l}\text { Hyaluronic } \\
\text { acid/TSG-6/inter- } \alpha- \\
\text { trypsin } \\
\text { inhibitor }\end{array}$ & $\begin{array}{l}\text { Incorporation of PTX3 into the hyaluronic acid-rich ECM } \\
\text { surrounding the pre-ovulatory oocyte (i.e., dependent on the } \\
\text { presence of l } \alpha \text { I and TSG-6) is essential for cumulus matrix stability } \\
\text { and female fertility (12) }\end{array}$ \\
\hline & Synaptogenesis & ND & $\begin{array}{l}\text { Pentraxin } 3 \text { regulates synaptic function by inducing AMPA } \\
\text { receptor clustering via ECM remodeling and beta1-integrin (60) }\end{array}$ \\
\hline & Bone turn-over & FGF2 & $\begin{array}{l}\text { PTX3 is expressed by osteoblast progenitors, and is essential for } \\
\text { matrix mineralization both in bone tissue homeostasis and fracture } \\
\text { repair (49) }\end{array}$ \\
\hline & Angiogenesis & FGFs & $\begin{array}{l}\text { PTX3 recognizes selected FGFs via its } \mathrm{N} \text {-terminal domain, and } \\
\text { inhibits their binding to FGF receptors, thus preventing } \\
\text { endothelial/smooth muscle cell proliferation in vitro and } \\
\text { angiogenesis/neointima formation in vivo (61) }\end{array}$ \\
\hline & Fibrinolysis & $\begin{array}{l}\text { Fibrinogen/ } \\
\text { fibrin/ } \\
\text { plasminogen }\end{array}$ & $\begin{array}{l}\text { PTX3 derived from macrophages and mesenchymal cells forms a } \\
\text { tripartite PTX3/fibrin/plasminogen complex at acidic pH that } \\
\text { promotes pericellular fibrinolysis (15) } \\
\text { In a mouse model of arterial thrombosis, PTX3 inhibits platelet } \\
\text { adhesion and aggregation by targeting fibrinogen and collagen (62) }\end{array}$ \\
\hline \multirow[t]{3}{*}{ Cancer } & Anti-tumoral & factor $\mathrm{H}$ & $\begin{array}{l}\text { In murine models of chemically induced mesenchymal and } \\
\text { epithelial carcinogenesis, PTX3 dampens cancer-related, } \\
\text { complement-dependent inflammation (14) }\end{array}$ \\
\hline & & FGFs & $\begin{array}{l}\text { PTX3 inhibits the FGF-driven tumor cell proliferation in vitro, tumor } \\
\text { growth, angiogenesis and metastatic potential in vivo in models of } \\
\text { melanoma, prostate, breast and lung cancer (63) }\end{array}$ \\
\hline & Pro-tumoral & Not defined & $\begin{array}{l}\text { PTX3 promotes tumor cell migration, invasion and metastasis, and } \\
\text { protein levels correlate with prognosis and/or tumor grade in } \\
\text { different types of cancer }(64,65)\end{array}$ \\
\hline
\end{tabular}

mindin, osteopontin, and vitronectin, interact with microbes and have opsonic activity $(53,66)$, thus suggesting a close evolutionary link between recognition of microbial moieties and ECM components.

In different mouse models of non-infectious tissue damage, deficiency of the long pentraxin PTX3 was associated with altered thrombotic response to the lesion, increased deposition and persistence of fibrin, followed by increased collagen deposition (15, 62, 67-69) (Figure 3).

Following tissue damage, PTX3 was induced in the blood and locally in response to TLR activation and IL- $1 \beta$ amplification (15). Interestingly, PTX3 is reported to be among the genes induced by thrombin in monocytes (70). At sites of wound, PTX3, released by neutrophils (9), localized in the clot and in the pericellular matrix of macrophages and PDGFR $\alpha^{+} \mathrm{FAP}^{+}$ cells of mesenchymal origin that collectively invade the wound site $(15,68)$.

In skin wounding, PTX3-deficiency was associated with increased deposition of fibrin, followed by increased deposition of collagen, fibroplasia, epithelial hyperplasia, and delayed healing (15). A premature contraction of the wound was observed in PTX3-deficient mice, in agreement with an augmented content of platelet-derived factors (e.g., thrombin, serotonin, PDGF, TGF $\beta$ ) known to be responsible of skin wound contraction by SMC located in the panniculus carnosus (71-73). Indeed, administration of pharmacological inhibitors of coagulation and platelet activation reverted these defects, including premature wound contraction and increased collagen deposition (15). Therefore, an altered haemostatic and fibrinolytic response triggered the alterations associated with PTX3-deficiency in skin wound healing.

In $\mathrm{CCl}_{4}$-induced liver injury, PTX3 was localized in necroinflammatory areas and fibrotic portal tracts, and was associated with neutrophils, macrophages and mesenchymal stromal cells (MSCs) (15). In this setting, PTX3-deficiency was associated with increased centrilobular thrombosis and fibrin deposition in necroinflammatory areas, followed by severe impairment of repair and fibrosis, as assessed by increased $\alpha$ $\mathrm{SMA}^{+}$fibroblastic cells and collagen deposition (15). Similar abnormalities were reported in different models of lung injury $(15,74)$. In addition, PTX3 played a protective role in a murine model of ischemic injury of the brain, where it was involved in the resolution of edema and glial scar formation (75). PTX3 administration reverted the IL-6/STAT3-dependent interstitial fibrosis in a mouse model of acute kidney injury (76).

Fibrin is deposited after tissue injury and its subsequent timely removal is essential for several aspects of tissue repair in major organs, as well as in a wide range of pathological conditions $(77,78)$. In these contexts, a defective fibrinolysis is described as an etiopathological factor leading to reduced remodeling and altered connective tissue formation (79-81). Macrophages and MSCs enter the wound site invading the inflammatory matrix through plasmin-mediated mechanisms, allowing fibrin removal and consequent deposition of granulation tissue rich in type 

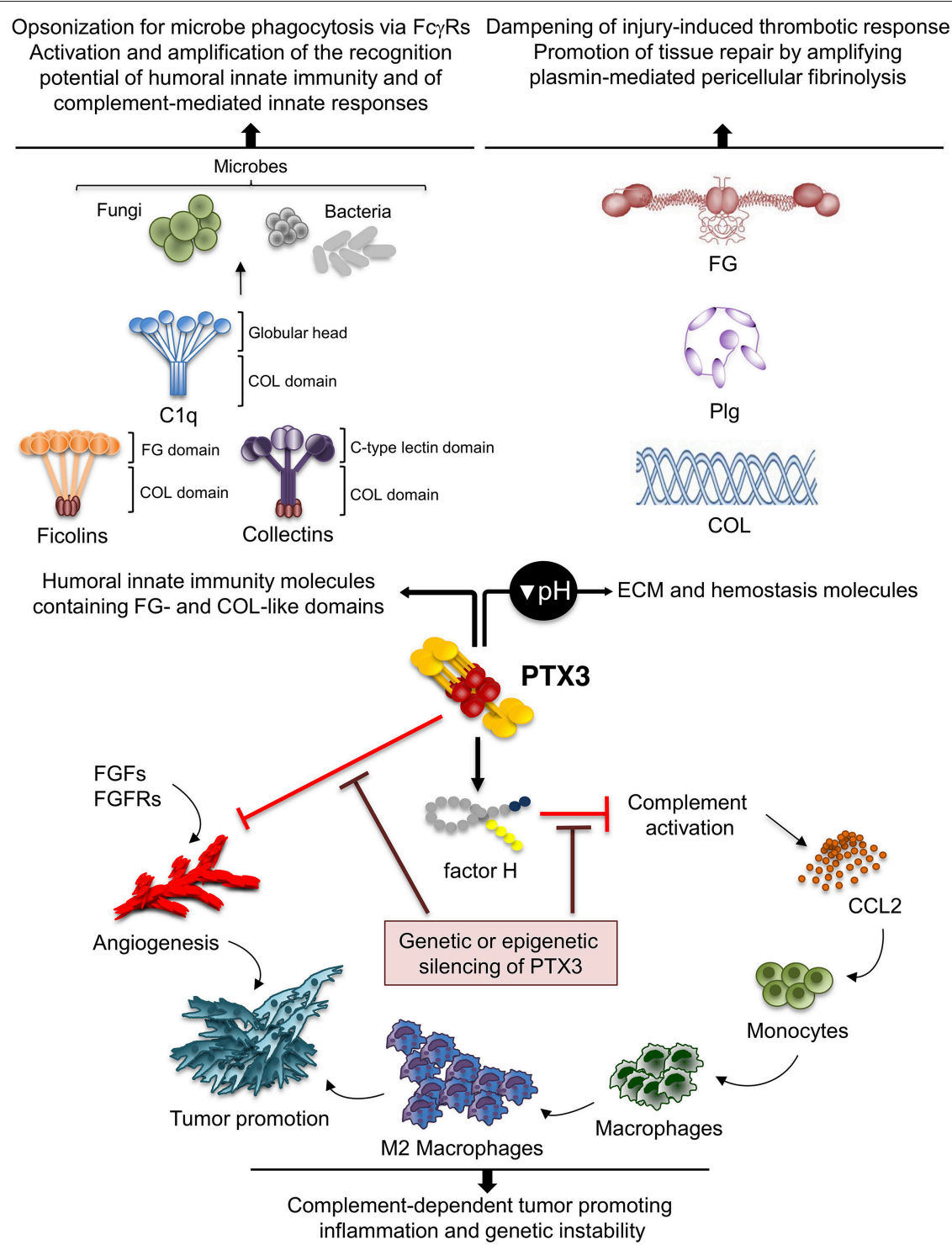

FIGURE 3 | Role of PTX3 at the crossroad between innate immunity, hemostasis and tissue repair, and cancer. By interacting with fibrinogen (FG)- and collagen (COL)-like domains of other fluid-phase PRMs, such as C1q, ficolins, and collectins, PTX3 amplifies the recognition potential of these members of the humoral innate immunity, favoring complement-mediated antimicrobial resistance, and effector functions (upper left panel). By interacting at acidic $\mathrm{pH}$ with fibrinogen/fibrin and collagen, as well as plasminogen (Plg), PTX3 tunes injury-induced thrombotic responses and favors pericellular fibrinolysis, contributing to tissue remodeling and repair (upper right panel). By interacting with factor $\mathrm{H}$ and FGFs, PTX3 controls complement-dependent tumor promoting inflammation, including CCL2-dependent macrophage recruitment and M2-like skewing, as well as FGF-dependent neo-angiogenesis. This anti-tumor potential of PTX3 is hampered by genetic or epigenetic silencing of PTX3 leading to enhanced tumor growth (lower panel).

I collagen, as well as other ECM proteins $(71,81,82)$. The alterations in tissue repair observed in PTX3-deficient mice have been attributed to defective plasmin-mediated invasion and fibrinolysis by tissue remodeling cells, namely macrophages and MSCs $(15,68)$. Also in vitro, PTX3-deficient macrophages and fibroblasts showed defective fibrinolytic activity (15), thus suggesting that PTX3 contributes to the progression of a normal and efficient pericellular fibrinolysis which promotes repair.

PTX3 was shown to interact specifically with Plg and fibrin at acidic $\mathrm{pH}$ (optimal range from 6.5 to 5.5), but not at neutral pH (15) (Figure 3). Interestingly, the interaction of PTX3 with members of the ficolin and collectin family, occurring through their fibrinogen-like domain and collagen domains, is facilitated in an acidic microenvironment (45, 83, 84). Acidification of the wound site, which occurs as a result of cellular metabolic adaptation to trauma-induced tissue hypoperfusion, has functional relevance in the healing outcome and involves several processes including cell adhesion, migration, and proliferation $(53,85)$. The interaction of PTX3 with fibrin and Plg occurs through different sites in its N-terminal domain 
and PTX3 does not interfere with the interaction between fibrin and Plg. In mapping experiments, PTX3 did not interact with the $\mathrm{Plg}$ Kringle 1 domain, indispensable for $\mathrm{Plg}$ initial recruitment on lysine-rich portions of fibrin and/or on cell surface, but specifically bound the Kringle 5 domain (15). This interaction could be crucial for triggering Plg conformational changes that allow a transition of the molecule from a closed-inactive to an open and functional form (86-88). This conformational transition is essential for Plg conversion into plasmin operated by Plg activators (PAs) and central in fibrin removal in the thrombus $(78,89)$. Indeed, in cell-free fibrinolysis assays, the interaction of PTX3 with Plg determined the enhancement of plasmin-mediated fibrin gel degradation triggered by urokinase PA (uPA) and tissue-type plasminogen activator (tPA) at acidic, but not neutral, pH. Plg activators are neutral proteases (90). The dependence on acidic pH of the interaction of PTX3 with fibrin and Plg ensures that it does not occur in the circulation but rather at sites of tissue repair and in thrombi, where it supports fibrinolysis in acidic environments. Thus, the acidic $\mathrm{pH}$ acts as a "switch on" signal for this function of PTX3 (Figure 3). The interaction with fibrin and Plg is restricted to PTX3, since no similar function has been reported for short pentraxins. Only one study reported the interaction of SAP with fibrin and consequent modulation of in vitro formation of clots (91), however the underlying molecular mechanism has never been characterized.

In a model of arterial thrombosis, PTX3 produced by the vessel wall had a critical protective role in the modulation of thrombus formation (62). Fibrinogen pre-incubation with PTX3 significantly reduced platelet aggregation in the presence of collagen. Likewise, pre-incubation of collagen with PTX3 attenuated platelet aggregation in the presence of fibrinogen. These effects were dependent, respectively, on the N-terminal or C-terminal domain of PTX3, and suggested that in arterial thrombosis PTX3 disfavored the pro-thrombotic activity of fibrinogen and collagen (62). PTX3 interacts with P-selectin and tunes P-selectin-dependent neutrophil extravasation (37). However, in arterial thrombosis PTX3 did not influence Pselectin-dependent platelet-leukocyte and platelet-endothelium aggregation $(62,92)$. Although initially PTX3 has been reported to induce tissue factor (TF) expression in endothelial cells and monocytes (93), subsequent in vitro and in vivo studies did not confirm this result $(15,62)$. Indeed, in the thrombosis model TF expression in the aorta of PTX3-deficient mice and controls was similar (62). These results are in line with the evidence that PTX3 plays protective functions in vascular pathologies. Indeed, PTX3 overexpression limited the neointimal thickening after rat carotid artery balloon injury (94) and PTX3-deficiency was associated with augmented infarct area following myocardial ischemia/reperfusion injury (13), increased atherosclerosis and augmented macrophage accumulation and inflammation in atherosclerotic plaques (95).

The administration of MSCs to acute or chronic wounds improves wound healing by increasing granulation tissue formation, accelerating re-epithelialization and stimulating angiogenesis through paracrine signaling (96), thus prompting new studies on the treatment of non-healing wounds resulting from burns (97) and Crohn's disease (98). In wounded skin, MSCs acted as a potent promoter of tissue repair and remodeling, whereas PTX3-deficient MSCs showed compromised recruitment and invasiveness at the site of damage, due to defective fibrinolysis, and therefore exerted a compromised therapeutic effect causing delayed healing (68).

Similar results were obtained in a mouse model of acid aspiration-dependent acute lung injury (69), mimicking acute respiratory distress syndrome (ARDS) caused by aspiration of gastric contents (99). In the mouse model, beneficial effects of treatment with MSCs on the early acute inflammatory reaction, pulmonary edema and long-term fibrotic evolution and pulmonary function have been observed. The administration of PTX3-deficient MSCs was less effective in limiting the pulmonary edema at $24 \mathrm{~h}$ after acid aspiration, and was associated with defective fibrinolytic activity, resulting at later time points in increased pulmonary fibrosis and therefore in a not significant increase of lung function. Levels of D-dimer significantly increased in mice after treatment with MSCs indicating their ability to modulate pulmonary fibrinolysis and thus affecting fibrotic scarring. The administration of PTX3-deficient MSCs resulted in decreased lung levels of D-dimer compared to PTX3competent MSCs, thus attributing to a defective fibrinolysis the observed reduced therapeutic effects of PTX3-deficient MSCs (69).

Recently, PTX3 has been identified as an important molecule contributing to bone homeostasis and remodeling (49). Under homoeostatic conditions, histological analysis of distal femurs of PTX3-deficient mice did not show differences in the number of active trabecular and endosteal $\mathrm{TRAP}^{+}$osteoclasts. However, micro-computed tomography showed a lower bone volume attributable to suppression of the osteoblast function. In a fracture and regeneration model of the tibia diaphysis, PTX3deficient mice showed a lower bone formation and repair rate than controls, in agreement with lower percentage of mineralized callous tissue and lower collagen I expression compared to controls. Under conditions of homeostasis and bone repair, the expression of PTX3 was associated with nonhematopoietic/non-endothelial periosteal cells, in particular, with $\mathrm{CD}_{51}{ }^{+}$and $\alpha-\mathrm{SMA}^{+}$osteoprogenitor subsets. FGF2 is expressed during the early stages of bone formation and is abundantly accumulated in the bone matrix, where it participates in osteoblastogenesis and skeletal remodeling (100). In agreement with the property of PTX3 to bind FGF2 and prevent FGF2-dependent activities, PTX3 reversed the negative effect of FGF2 on osteoblast differentiation from bone marrow stromal cells in vitro, and the PTX3 Nterminal domain alone recapitulated this activity. Therefore, PTX3 produced by osteoblast lineage cells, acts as a bone protective factor, important to unlock osteoblast maturation by antagonizing the FGF2 effect during bone formation (49). Bone formation during fracture repair initiates around extravascular deposits of fibrin-rich matrix and subsequent defects in fibrin clearance from the fracture site severely impair healing (101). Fibrinogen depletion in Plg-deficient animals restores a normal fracture repair (102), thus proving that inefficient fibrin turnover is essential for bone repair. Therefore, further studies are needed to address the relevance 
of PTX3-dependent modulation of the fibrinolytic system in bone repair.

All together, these studies have provided several lines of evidence that the involvement of PTX3 in tissue remodeling and repair depends on the recognition of matrix molecules and highlight the connection and interplay between haemostasis and immunity (Figure 3).

\section{ROLE OF PTX3 IN CANCER}

Inflammation is a component of the tumor microenvironment promoting tumor development and growth (103). Since PTX3 is expressed in inflammatory conditions and acts as a tuner of complement-activation and leukocyte recruitment, it was hypothesized that PTX3 was involved in cancer-related inflammation. Genetic studies in mice showed that PTX3deficiency caused increased susceptibility to mesenchymal and epithelial carcinogenesis in the models of 3-methylcholanthrene (3-MCA)-induced sarcomagenesis, and 7,12-dimethylbenz [a] anthracene/terephthalic acid (DMBA/TPA)-induced skin carcinogenesis (14). In these tumors, infiltrating macrophages and endothelial cells were the major source of PTX3 in response to locally produced IL-1. PTX3-deficient tumors were characterized by increased macrophage infiltration, proinflammatory cytokine production, complement activation, and angiogenesis, as well as increased oxidative DNA damage and genetic instability, compared to wild type tumors (14). In this context, PTX3 regulated complement activation by interacting with factor $\mathrm{H}$, a complement regulator, and as a consequence, macrophage recruitment and M2-like polarization (14) (Figure 3).

These data are in line with recent studies showing that the anaphylatoxins $\mathrm{C} 3 \mathrm{a}$ and $\mathrm{C} 5 \mathrm{a}$ may contribute to cancer-related inflammation, recruit myeloid suppressor cells, and promote IL- $1 \beta$ and IL-17 response in neutrophils thus promoting colon carcinogenesis (104-107).

In addition to regulate complement, PTX3 was shown to bind selected fibroblast growth factors (FGFs), including FGF2, and FGF8b through the N-terminal domain, and inhibit FGFdependent angiogenic responses (6). This effect was shown to be responsible of the anti-tumor activity of PTX3 in FGF-dependent transplanted murine tumors, including prostate cancer and melanoma and fibrosarcoma (108-110) (Figure 3). The role of PTX3-mediated anti-angiogenic activity has not been addressed so far in primary carcinogenesis.

In line with these preclinical studies, the human PTX3 promoter and regulatory regions were shown to be epigenetically modified through hypermethylation in selected human mesenchymal and epithelial cancers, such as esophageal squamous cell carcinoma (111) and colorectal cancer $(14,18,112)$, leading to silencing of PTX3 protein expression. Thus, genetic studies in mice and epigenetic studies in humans demonstrate that PTX3 behaves as an extrinsic oncosuppressor gene by acting at the level of complement-mediated, macrophage-sustained, tumor promoting inflammation.

In contrast to the genetic evidence outlined above, several studies performed with PTX3 overexpressing cells suggest that the protein may play a pro-tumorigenic role by promoting tumor cell migration and invasion (head and neck tumors, cervical cancer) or proliferation (glioma), epithelial-mesenchymal transition (hepatocellular carcinoma) and macrophage chemotaxis $(64,65,113,114)$. In basal-like breast cancers, PTX3 was found to be a critical target of oncogenic phosphoinositide 3-kinase signaling and NF- $\mathrm{B}$-dependent pathways, and to be associated with PI3K-induced stem cell-like traits (115). However, none of these pro-tumoral effects of PTX3 has been confirmed in gene targeted animals or in carcinogenesis models.

These contradictory results suggest that PTX3 may have a dual role in cancer, likely depending on the type of cancer, or on the cells producing it, in particular tumor cells or infiltrating macrophages, fibroblasts and endothelial cells. Further genetic studies in mice and humans will be necessary to clarify these context-dependent findings.

\section{PTX3 AS MARKER OF CANCER PROGRESSION}

Several lines of evidence indicate that PTX3 could be a local or systemic marker of cancer-related inflammation. Upregulation of PTX3 gene expression was observed associated to a stromal signature in ovarian cancer (116), and has been described in aggressive breast cancer and distant bone metastases (117119), anaplastic thyroid carcinoma (120), soft tissue liposarcoma (121), prostate cancer (122), and glioblastoma (123). Increased circulating levels of PTX3 were observed in myeloproliferative neoplasms (124), soft tissue sarcomas (125), lung cancers (126-128), pancreatic carcinomas (129), gliomas (130), and hepatocellular carcinomas (131). In pancreatic carcinoma, high PTX3 levels were associated with advanced clinical stage and poor overall survival. In the same cohort of patients with invasive ductal pancreatic carcinoma at stage III and IV, plasmatic CRP levels were similarly associated with a worst prognosis (129).

Different studies analyzed the role of PTX3 as biomarker in lung cancer. Through a proteomic effort, Planque et al. reported in 2009 that PTX3 is produced by lung cancer cells. This result was confirmed in patients with lung cancer, in which PTX3 plasma levels resulted significantly increased compared to healthy subjects (126). It was subsequently observed that PTX3 circulating levels were related to disease aggressiveness and progression, irrespective to the subtypes and histotypes of lung cancer (127). In addition, ROC analysis indicated that PTX3 could discriminate between cancer patients and heavy smokers at high risk for lung cancer (127). Similarly, high PTX3 levels were correlated with worse progression-free survival in patients with lung cancer and chronic obstructive pulmonary disease (132), and with overall survival and disease-free survival in small-cell lung carcinoma (SCLC) (133). A recent study on 1358 individuals at high risk for lung cancer demonstrated that PTX3 levels were not predictive of pathology occurrence (128). In the 110 patients of this cohort that developed resectable lung cancer, preoperative PTX3 plasma levels were higher compared with those of cancer-free heavy smokers, but were not predictor of outcomes (128).

In prostate cancer patients, circulating levels of PTX3 were higher compared to patients with prostatic inflammation, 
while serum levels of prostate-specific antigen (PSA) and CRP were not different between the two groups (134). In CRC, PTX3 circulating levels were significantly increased compared to healthy individuals or to patients with colorectal polyps, representing an independent prognostic factor for CRC patients (135). PTX3 levels were reduced at discharge after surgery, and a subsequent increase during the follow-up was associated to recurrence. Preoperative PTX3 levels were significantly associated to clinical stage and to a better postoperative prognosis in a cohort of 263 primary CRC patients (136). In another small group of CRC patients, PTX3 serum levels combined with CXCL8 and VEGF levels were efficiently predicting relapsing cases (137). Since epigenetic studies showed PTX3 silencing in colorectal tumor cells (18), increased PTX3 plasma levels in these patients reasonably reflect cancer-related inflammation associated with tumor growth. Patients with hepatocellular carcinoma (HCC) showed higher PTX3 levels than individuals with fibrosis (131). Interestingly, in these patients the A/A genotype for rs 1840680 and rs2305619, resulting in higher PTX3 plasma levels, was also significantly associated with the presence of HCC.

Beside an evaluation of PTX3 as soluble biomarker in cancer, some reports also investigated PTX3 expression in cancer tissues. In hepatocellular carcinoma, PTX3 expression was analyzed after liver resection in tumoral and adjacent normal tissue and a higher PTX3 expression was observed in the tumoral area. PTX3 expression was correlated with advanced stage, larger tumor size, presence of intra-hepatic metastases, portal vein tumor thrombosis and liver cirrhosis (65). Overall, high PTX3 expression in tumor tissue from HCC was associated with lower survival after surgery. Immunohistochemical analysis on tissue specimens from lung cancer revealed an interstitial expression of PTX3 in the neoplastic area associated with shorter survival, while no staining was observed in normal lung parenchyma (128). In tissue samples from prostate cancer patients, PTX3 is expressed at higher levels compared to patients with prostatic inflammation (134).

Overall the data reported above strongly suggest that PTX3 is overexpressed locally or systemically in different neoplastic conditions, and could likely represent a novel promising prognostic factor for cancer patients. In particular, as discussed above and by Giacomini et al. (63), PTX3 originated from endothelial cells, tumor-associated fibroblasts and infiltrating myeloid cells likely reflects microenvironment or systemic inflammation associated with tumor progression, and not its involvement in the pathogenesis. Indeed, the role of PTX3 in neoplastic transformation and growth has been shown to depend on the context and to be influenced by its property to interact with different molecules in the tumor environment.

\section{CONCLUDING REMARKS}

Based on genetic studies in mice and human genetic associations, PTX3 is a well-recognized mediator of innate resistance to selected infections, acting by modulating complement activation, opsonizing microbes and facilitating their clearance through phagocytosis. Moreover, by interacting with the fibrinogen-like and collagen-like domains of ficolins and collectins, PTX3 amplifies the recognition potential of the humoral innate immunity (1) (Figure 3). These lines of evidence provide the rational for therapeutic and diagnostic translation of this molecule in infectious conditions.

Several studies presented in this review also indicate that PTX3 is involved in tissue remodeling and repair in sterile conditions through the recognition of matrix molecules, and regulates the thrombotic response and fibrin remodeling, thus playing a non-redundant role in the orchestration of the tissue repair process (Figure 3). Other humoral PRMs interact with ECM components (e.g., C1q, collectins, CRP, SAP), or contain collagen- and fibrinogen-like domains (e.g., ficolins, MBL, collectins), and several ECM molecules recognize microbial moieties and have opsonic activity (e.g., fibronectin, mindin, osteopontin, vitronectin). These lines of evidence support the view that inflammation, innate immunity, haemostasis, and tissue repair are functionally linked and that the recognition of microbial moieties and extracellular matrix molecules by the humoral arm of innate immunity is evolutionarily conserved.

Studies reported here finally show that PTX3 is involved in tuning carcinogenesis through the modulation of cancer-related inflammation or angiogenesis in specific cancer types (Figure 3). However, other studies propose that in specific models PTX3 has a pro-tumorigenic function, by promoting tumor cell migration and invasion and macrophage infiltration, suggesting that PTX3 may have different functions on carcinogenesis depending on the tissue and cancer type, and possibly cell- and stimulusdependent PTX3 glycosylation (and sialylation) profiles, which needs further dissection.

Cancer is considered a "non-healing wound" (138), since wound-healing responses favoring tumor growth are activated in the tumor microenvironment. These include extravascular deposition of fibrin that acts as a provisional stroma for stromal and immune cells migration, angiogenesis and ECM deposition and remodeling (139). Fibrin degradation, vascular resorption and collagen synthesis result in formation of dense fibrous connective tissue ("scar" in wounds and "desmoplasia" in cancer). These responses are similar in tumors and wounds, but in tumors they are not self-limited. PTX3 by interacting with fibrin matrix (15), FGF2 (109), and complement components (14) regulates the main common processes in tissue repair (139-141) and in tumor-promoting angiogenesis and inflammation (Table 1) $(61,142,143)$, thus suggesting that the roles of PTX3 in tissue repair and cancer are functionally associated.

\section{AUTHOR CONTRIBUTIONS}

$\mathrm{CG}$ and $\mathrm{BB}$ revised the manuscript and redacted the final version. $\mathrm{AD}, \mathrm{MS}, \mathrm{AI}, \mathrm{EM}, \mathrm{AM}, \mathrm{CG}$, and $\mathrm{BB}$ contributed to the writing of the manuscript. 


\section{ACKNOWLEDGMENTS}

The financial support of Fondazione Cariplo [Contract no. 20150564 (to AM) and 2016-0568 (to EM)]; Ministero della Salute (RF-2013-02355470 to CG, GR-2011-02349539 to AI); Ministry

\section{REFERENCES}

1. Bottazzi B, Doni A, Garlanda C, Mantovani A. An integrated view of humoral innate immunity: pentraxins as a paradigm. Annu Rev Immunol. (2010) 28:157-83. doi: 10.1146/annurev-immunol-030409-101305

2. Pepys MB, Hirschfield GM. C-reactive protein: a critical update. J Clin Invest. (2003) 111:1805-12. doi: 10.1172/JCI200318921

3. Garlanda C, Bottazzi B, Magrini E, Inforzato A, Mantovani A. Ptx3, a humoral pattern recognition molecule, in innate immunity, tissue repair, and cancer. Physiol Rev. (2018) 98:623-39. doi: 10.1152/physrev.00016.2017

4. Doni A, Peri G, Chieppa M, Allavena P, Pasqualini F, Vago L, et al. Production of the soluble pattern recognition receptor PTX3 by myeloid, but not plasmacytoid, dendritic cells. Eur J Immunol. (2003) 33:2886-93. doi: 10.1002/eji.200324390

5. Woo JM, Kwon MY, Shin DY, Kang YH, Hwang N, Chung SW. Human retinal pigment epithelial cells express the long pentraxin PTX3. Mol Vis. (2013) 19:303-10.

6. Presta M, Camozzi M, Salvatori G, Rusnati M. Role of the soluble pattern recognition receptor PTX3 in vascular biology. J Cell Mol Med. (2007) 11:723-38. doi: 10.1111/j.1582-4934.2007.00061.x

7. Norata GD, Marchesi P, Pirillo A, Uboldi P, Chiesa G, Maina V, et al. Long pentraxin 3, a key component of innate immunity, is modulated by high-density lipoproteins in endothelial cells. Arterioscler Thromb Vasc Biol. (2008) 28:925-31. doi: 10.1161/ATVBAHA.107.160606

8. Imamura M, Kawasaki T, Savchenko AS, Ohashi R, Jiang S, Miyamoto $\mathrm{K}$, et al. Lipopolysaccharide induced expression of pentraxin 3 in human neutrophils and monocyte-derived macrophages. Cell Immunol. (2007) 248:86-94. doi: 10.1016/j.cellimm.2007.09.003

9. Jaillon S, Peri G, Delneste Y, Fremaux I, Doni A, Moalli F, et al. The humoral pattern recognition receptor PTX3 is stored in neutrophil granules and localizes in extracellular traps. J Exp Med. (2007) 204:793-804. doi: 10.1084/jem.20061301

10. Doni A, Michela M, Bottazzi B, Peri G, Valentino S, Polentarutti N, et al. Regulation of PTX3, a key component of humoral innate immunity in human dendritic cells: stimulation by IL-10 and inhibition by IFN-gamma. $J$ Leukoc Biol. (2006) 79:797-802. doi: 10.1189/jlb.0905493

11. Doni A, Mantovani G, Porta C, Tuckermann J, Reichardt HM, Kleiman A, et al. Cell-specific regulation of PTX3 by glucocorticoid hormones in hematopoietic and non-hematopoietic cells. J Biol Chem. (2008) 283:2998392. doi: 10.1074/jbc.M805631200

12. Camaioni A, Klinger FG, Campagnolo L, Salustri A. The influence of Pentraxin 3 on the ovarian function and its impact on fertility. Front Immunol. (2018) 9:2808. doi: 10.3389/fimmu.2018.02808

13. Salio M, Chimenti S, De Angelis N, Molla F, Maina V, Nebuloni $\mathrm{M}$, et al. Cardioprotective function of the long pentraxin PTX3 in acute myocardial infarction. Circulation. (2008) 117:1055-64. doi: 10.1161/CIRCULATIONAHA.107.749234

14. Bonavita E, Gentile S, Rubino M, Maina V, Papait R, Kunderfranco $\mathrm{P}$, et al. PTX3 is an extrinsic oncosuppressor regulating complementdependent inflammation in cancer. Cell. (2015) 160:700-14. doi: 10.1016/j.cell.2015.01.004

15. Doni A, Musso T, Morone D, Bastone A, Zambelli V, Sironi M, et al. An acidic microenvironment sets the humoral pattern recognition molecule PTX3 in a tissue repair mode. J Exp Med. (2015) 212:905-25. doi: 10.1084/jem.20141268

16. Han B, Mura M, Andrade CF, Okutani D, Lodyga M, dos Santos CC, et al. TNFalpha-induced long pentraxin PTX3 expression in human lung epithelial cells via JNK. J Immunol. (2005) 175:8303-11. doi: 10.4049/jimmunol.175.12.8303 of Education, University and Research (PRIN 2015YYKPNN); the European Research Council (ERC - N 669415 to AM); Fondazione Beppe e Nuccy Angiolini; and the Italian Association for Cancer Research (AIRC IG 19014 to AM, AIRC IG 21714 to CG, AIRC 5x1000 9962 and 21147) is gratefully acknowledged.

17. Guo TM, Huang LL, Liu K, Ke L, Luo ZJ, Li YQ, et al. Pentraxin 3 (PTX3) promoter methylation associated with PTX3 plasma levels and neutrophil to lymphocyte ratio in coronary artery disease. J Geriatr Cardiol. (2016) 13:712-7. doi: 10.11909/j.issn.1671-5411.2016.08.010

18. Rubino M, Kunderfranco P, Basso G, Greco CM, Pasqualini F, Serio $S$, et al. Epigenetic regulation of the extrinsic oncosuppressor PTX3 gene in inflammation and cancer. Oncoimmunology. (2017) 6:e1333215. doi: 10.1080/2162402X.2017.1333215

19. Sica A, Mantovani A. Macrophage plasticity and polarization: in vivo veritas. J Clin Invest. (2012) 122:787-95. doi: 10.1172/JCI59643

20. Cunha C, Aversa F, Lacerda JF, Busca A, Kurzai O, Grube M, et al. Genetic PTX3 deficiency and aspergillosis in stem-cell transplantation. $N$ Engl J Med (2014) 370:421-32. doi: 10.1056/NEJMoa1211161

21. Wojtowicz A, Lecompte TD, Bibert S, Manuel O, Rueger S, Berger C, et al. PTX3 Polymorphisms and invasive mold infections after solid organ transplant. Clin Infect Dis. (2015) 61:619-22. doi: 10.1093/cid/ civ386

22. Fisher CE, Hohl TM, Fan W, Storer BE, Levine DM, Zhao LP, et al. Validation of single nucleotide polymorphisms in invasive aspergillosis following hematopoietic cell transplantation. Blood. (2017) 129:2693-701. doi: 10.1182/blood-2016-10-743294

23. Brunel AS, Wojtowicz A, Lamoth F, Spertini O, Neofytos D, Calandra T, et al. Pentraxin-3 polymorphisms and invasive mold infections in acute leukemia patients with intensive chemotherapy. Haematologica. (2018) 103:e527-30. doi: 10.3324/haematol.2018.195453

24. Olesen R, Wejse C, Velez DR, Bisseye C, Sodemann M, Aaby P, et al. DCSIGN (CD209), Pentraxin 3 and vitamin D receptor gene variants associate with pulmonary tubercolosis risk in West-Africans. Genes Immun. (2007) 8:456-67. doi: 10.1038/sj.gene.6364410

25. Chiarini M, Sabelli C, Melotti P, Garlanda C, Savoldi G, Mazza C, et al. PTX3 genetic variations affect the risk of Pseudomonas aeruginosa airway colonization in cystic fibrosis patients. Genes Immun. (2010) 11:665-70 doi: 10.1038/gene.2010.41

26. Barbati E, Specchia C, Villella M, Rossi ML, Barlera S, Bottazzi B, et al. Influence of pentraxin 3 (PTX3) genetic variants on myocardial infarction risk and PTX3 plasma levels. PLoS ONE. (2012) 7:e53030. doi: 10.1371/journal.pone.0053030

27. Garlanda C, Bottazzi B, Bastone A, Mantovani A. Pentraxins at the crossroads between innate immunity, inflammation, matrix deposition, and female fertility. Annu Rev Immunol. (2005) 23:337-66. doi: 10.1146/annurev.immunol.23.021704.115756

28. Bottazzi B, Vouret-Craviari V, Bastone A, De Gioia L, Matteucci C, Peri $\mathrm{G}$, et al. Multimer formation and ligand recognition by the long pentraxin PTX3. Similarities and differences with the short pentraxins C-reactive protein and serum amyloid P component. J Biol Chem. (1997) 272:32817-23. doi: $10.1074 /$ jbc.272.52.32817

29. Dyson HJ. Making sense of intrinsically disordered proteins. Biophys J. (2016) 110:1013-6. doi: 10.1016/j.bpj.2016.01.030

30. Goodman AR, Cardozo T, Abagyan R, Altmeyer A, Wisniewski HG, Vilcek J. Long pentraxins: an emerging group of proteins with diverse functions. Cytokine Growth Factor Rev. (1996) 7:191-202. doi: 10.1016/1359-6101(96)00019-6

31. Introna M, Alles VV, Castellano M, Picardi G, De Gioia L, Bottazzai B, et al. Cloning of mouse ptx3, a new member of the pentraxin gene family expressed at extrahepatic sites. Blood. (1996) 87:1862-72.

32. Inforzato A, Peri G, Doni A, Garlanda C, Mantovani A, Bastone A, et al. Structure and function of the long pentraxin PTX3 glycosidic moiety: finetuning of the interaction with $\mathrm{Clq}$ and complement activation. Biochemistry. (2006) 45:11540-51. doi: 10.1021/bi0607453 
33. Inforzato A, Baldock C, Jowitt TA, Holmes DF, Lindstedt R, Marcellini M, et al. The angiogenic inhibitor long pentraxin PTX3 forms an asymmetric octamer with two binding sites for FGF2. J Biol Chem. (2010) 285:17681-92. doi: 10.1074/jbc.M109.085639

34. Inforzato A, Rivieccio V, Morreale AP, Bastone A, Salustri A, Scarchilli L, et al. Structural characterization of PTX3 disulfide bond network and its multimeric status in cumulus matrix organization. J Biol Chem. (2008) 283:10147-61. doi: 10.1074/jbc.M708535200

35. Reading PC, Bozza S, Gilbertson B, Tate M, Moretti S, Job ER, et al. Antiviral activity of the long chain Pentraxin PTX3 against influenza viruses. J Immunol. (2008) 180:3391-8. doi: 10.4049/jimmunol.180.5.3391

36. Job ER, Bottazzi B, Short KR, Deng YM, Mantovani A, Brooks AG, et al. A single amino acid substitution in the hemagglutinin of $\mathrm{H} 3 \mathrm{~N} 2$ subtype influenza A viruses is associated with resistance to the long pentraxin PTX3 and enhanced virulence in mice. J Immunol. (2014) 192:271-81. doi: 10.4049/jimmunol.1301814

37. Deban L, Castro Russo R, Sironi M, Moalli F, Scanziani M, Zambelli V, et al. Regulation of leukocyte recruitment by the long pentraxin PTX3. Nat Immunol. (2010) 11:328-34. doi: 10.1038/ni.1854

38. Inforzato A, Doni A, Barajon I, Leone R, Garlanda C, Bottazzi B, et al. PTX3 as a paradigm for the interaction of pentraxins with the complement system. Semin Immunol. (2013) 25:79-85. doi: 10.1016/j.smim.2013.05.002

39. Camozzi M, Rusnati M, Bugatti A, Bottazzi B, Mantovani A, Bastone A, et al. Identification of an antiangiogenic FGF2-binding site in the $\mathrm{N}$ terminus of the soluble pattern recognition receptor PTX3. J Biol Chem. (2006) 281:22605-13. doi: 10.1074/jbc.M601023200

40. Moalli F, Doni A, Deban L, Zelante T, Zagarella S, Bottazzi B, et al. Role of complement and $\mathrm{Fc}$ \{gamma\} receptors in the protective activity of the long pentraxin PTX3 against Aspergillus fumigatus. Blood. (2010) 116:5170-80. doi: 10.1182/blood-2009-12-258376

41. Ievoli E, Lindstedt $\mathrm{R}$, Inforzato A, Camaioni A, Palone F, Day AJ, et al. Implication of the oligomeric state of the N-terminal PTX3 domain in cumulus matrix assembly. Matrix Biol. (2011) 30:330-7. doi: 10.1016/j.matbio.2011.05.002

42. Leali D, Inforzato A, Ronca R, Bianchi R, Belleri M, Coltrini D, et al. Long pentraxin 3/tumor necrosis factor-stimulated gene-6 interaction: a biological rheostat for fibroblast growth factor 2-mediated angiogenesis. Arterioscler Thromb Vasc Biol. (2012) 32:696-703. doi: 10.1161/ATVBAHA.111.243998

43. Deban L, Jarva H, Lehtinen MJ, Bottazzi B, Bastone A, Doni A, et al. Binding of the long pentraxin PTX3 to Factor H: Interacting domains and function in the regulation of complement activation. J Immunol. (2008) 181:8433-40. doi: 10.4049/jimmunol.181.12.8433

44. Parente R, Clark SJ, Inforzato A, Day AJ. Complement factor $\mathrm{H}$ in host defense and immune evasion. Cell Mol Life Sci. (2017) 74:1605-24. doi: 10.1007/s00018-016-2418-4

45. Ma YJ, Doni A, Skjoedt MO, Honore C, Arendrup M, Mantovani A, et al. Heterocomplexes of mannose-binding lectin and the pentraxins PTX3 or serum amyloid P component trigger cross-activation of the complement system. J Biol Chem. (2011) 286:3405-17. doi: 10.1074/jbc.M110.190637

46. Emsley J, White HE, O'Hara BP, Oliva G, Srinivasan N, Tickle IJ, et al. Structure of pentameric human serum amyloid P component. Nature. (1994) 367:338-45. doi: 10.1038/367338a0

47. Thompson D, Pepys MB, Wood SP. The physiological structure of human C-reactive protein and its complex with phosphocholine. Structure. (1999) 7:169-77. doi: 10.1016/S0969-2126(99)80023-9

48. Shrive AK, Metcalfe AM, Cartwright JR, Greenhough TJ. C-reactive protein and SAP-like pentraxin are both present in Limulus polyphemus haemolymph: crystal structure of Limulus SAP. J Mol Biol. (1999) 290:9971008. doi: 10.1006/jmbi.1999.2956

49. Grcevic D, Sironi M, Valentino S, Deban L, Cvija H, Inforzato A, et al. The long Pentraxin 3 plays a role in bone turnover and repair. Front Immunol. (2018) 9:417. doi: 10.3389/fimmu.2018.00417

50. Baranova NS, Inforzato A, Briggs DC, Tilakaratna V, Enghild JJ, Thakar D, et al. Incorporation of pentraxin 3 into hyaluronan matrices is tightly regulated and promotes matrix cross-linking. J Biol Chem. (2014) 289:30481-98. doi: $10.1074 /$ jbc.M114.568154

51. Medzhitov R. Origin and physiological roles of inflammation. Nature. (2008) 454:428-35. doi: 10.1038/nature07201
52. Rakoff-Nahoum S, Medzhitov R. Toll-like receptors and cancer. Nat Rev Cancer. (2009) 9:57-63. doi: 10.1038/nrc2541

53. Doni A, D'Amico G, Morone D, Mantovani A, Garlanda C. Humoral innate immunity at the crossroad between microbe and matrix recognition: The role of PTX3 in tissue damage. Semin Cell Dev Biol. (2016) 61:31-40. doi: 10.1016/j.semcdb.2016.07.026

54. Takeda K, Kaisho T, Akira S. Toll-like receptors. Annu Rev Immunol. (2003) 21:335-76. doi: 10.1146/annurev.immunol.21.120601.141126

55. Holmskov U, Thiel S, Jensenius JC. Collections and ficolins: humoral lectins of the innate immune defense. Annu Rev Immunol. (2003) 21:547-78. doi: 10.1146/annurev.immunol.21.120601.140954

56. Oikonomopoulou K, Ricklin D, Ward PA, Lambris JD. Interactions between coagulation and complement-their role in inflammation. Semin Immunopathol. (2012) 34:151-65. doi: 10.1007/s00281-0110280-x

57. Pilling $\mathrm{D}$, Gomer RH. Persistent lung inflammation and fibrosis in serum amyloid P component (APCs-/-) knockout mice. PLoS ONE. (2014) 9:e93730. doi: 10.1371/journal.pone.0093730

58. Cox N, Pilling D, Gomer RH. DC-SIGN activation mediates the differential effects of SAP and CRP on the innate immune system and inhibits fibrosis in mice. Proc Natl Acad Sci USA. (2015) 112:8385-90. doi: 10.1073/pnas.1500956112

59. Bottazzi B, Inforzato A, Messa M, Barbagallo M, Magrini E, Garlanda $\mathrm{C}$, et al. The pentraxins PTX3 and SAP in innate immunity, regulation of inflammation and tissue remodelling. J Hepatol. (2016) 64:1416-27. doi: 10.1016/j.jhep.2016.02.029

60. Fossati G, Pozzi D, Canzi A, Mirabella F, Valentino S, Morini R, et al. Pentraxin 3 regulates synaptic function by inducing AMPA receptor clustering via ECM remodeling and betal-integrin. EMBO J. (2019) 38:e99529. doi: 10.15252/embj.201899529

61. Presta M, Foglio E, Churruca Schuind A, Ronca R. Long Pentraxin3 modulates the angiogenic activity of fibroblast growth factor-2. Front Immunol. (2018) 9:2327. doi: 10.3389/fimmu.2018.02327

62. Bonacina F, Barbieri SS, Cutuli L, Amadio P, Doni A, Sironi M, et al. Vascular pentraxin 3 controls arterial thrombosis by targeting collagen and fibrinogen induced platelets aggregation. Biochim Biophys Acta. (2016) 1862:1182-90. doi: 10.1016/j.bbadis.2016.03.007

63. Giacomini A, Ghedini GC, Presta M, Ronca R. Long pentraxin 3: a novel multifaceted player in cancer. Biochim Biophys Acta Rev Cancer. (2018) 1869:53-63. doi: 10.1016/j.bbcan.2017.11.004

64. Chang WC, Wu SL, Huang WC, Hsu JY, Chan SH, Wang JM, et al. PTX3 gene activation in EGF-induced head and neck cancer cell metastasis. Oncotarget. (2015) 6:7741-57. doi: 10.18632/oncotarget.3482

65. Song T, Wang C, Guo C, Liu Q, Zheng X. Pentraxin 3 overexpression accelerated tumor metastasis and indicated poor prognosis in hepatocellular carcinoma via driving epithelial-mesenchymal transition. J Cancer. (2018) 9:2650-8. doi: 10.7150/jca. 25188

66. Doni A, Garlanda C, Mantovani A. Innate immunity, hemostasis and matrix remodeling: PTX3 as a link. Semin Immunol. (2016b) 28:570-7. doi: $10.1016 /$ j.smim.2016.10.012

67. Han B, Haitsma JJ, Zhang Y, Bai X, Rubacha M, Keshavjee S, et al. Long pentraxin PTX3 deficiency worsens LPS-induced acute lung injury. Intensive Care Med. (2011) 37:334-42. doi: 10.1007/s00134-0102067-2

68. Cappuzzello C, Doni A, Dander E, Pasqualini F, Nebuloni M, Bottazzi B, et al. Mesenchymal stromal cell-derived PTX3 promotes wound healing via fibrin remodeling. J Invest Dermatol. (2016) 136:293-300. doi: 10.1038/JID.2015.346

69. Mauri T, Zambelli V, Cappuzzello C, Bellani G, Dander E, Sironi M, et al. Intraperitoneal adoptive transfer of mesenchymal stem cells enhances recovery from acid aspiration acute lung injury in mice. Intensive Care Med Exp. (2017) 5:13. doi: 10.1186/s40635-017-0126-5

70. Lopez ML, Bruges G, Crespo G, Salazar V, Deglesne PA, Schneider H, et al. Thrombin selectively induces transcription of genes in human monocytes involved in inflammation and wound healing. Thromb Haemost. (2014) 112:992-1001. doi: 10.1160/th14-01-0034

71. Singer AJ, Clark RA. Cutaneous wound healing. N Engl J Med. (1999) 341:738-46. doi: 10.1056/NEJM199909023411006 
72. Tomasek JJ, Gabbiani G, Hinz B, Chaponnier C, Brown RA. Myofibroblasts and mechano-regulation of connective tissue remodelling. Nat Rev Mol Cell Biol. (2002) 3:349-63. doi: 10.1038/nrm809

73. Wong VW, Sorkin M, Glotzbach JP, Longaker MT, Gurtner GC. Surgical approaches to create murine models of human wound healing. J Biomed Biotechnol. (2011) 2011:969618. doi: 10.1155/2011/969618

74. Han B, Ma X, Zhang J, Zhang Y, Bai X, Hwang DM, et al. Protective effects of long pentraxin PTX3 on lung injury in a severe acute respiratory syndrome model in mice. Lab Invest. (2012) 92:1285-96. doi: 10.1038/labinvest.2012.92

75. Rodriguez-Grande B, Swana M, Nguyen L, Englezou P, Maysami S, Allan SM, et al. The acute-phase protein PTX3 is an essential mediator of glial scar formation and resolution of brain edema after ischemic injury. J Cereb Blood Flow Metab. (2014) 34:480-8. doi: 10.1038/jcbfm.2013.224

76. Xiao Y, Yang N, Zhang Q, Wang Y, Yang S, Liu Z. Pentraxin 3 inhibits acute renal injury-induced interstitial fibrosis through suppression of IL-6/Stat3 pathway. Inflammation. (2014) 37:1895-901. doi: 10.1007/s10753-014-9921-2

77. Carmeliet P, Schoonjans L, Kieckens L, Ream B, Degen J, Bronson R, et al. Physiological consequences of loss of plasminogen activator gene function in mice. Nature. (1994) 368:419-24. doi: 10.1038/368419a0

78. Bugge TH, Kombrinck KW, Flick MJ, Daugherty CC, Danton MJ, Degen JL. Loss of fibrinogen rescues mice from the pleiotropic effects of plasminogen deficiency. Cell. (1996) 87:709-19. doi: 10.1016/S0092-8674(00) 81390-2

79. Tuan TL, Zhu JY, Sun B, Nichter LS, Nimni ME, Laug WE. Elevated levels of plasminogen activator inhibitor-1 may account for the altered fibrinolysis by keloid fibroblasts. J Invest Dermatol. (1996) 106:1007-11. doi: 10.1111/1523-1747.ep12338552

80. Idell S. Endothelium and disordered fibrin turnover in the injured lung: newly recognized pathways. Crit Care Med. (2002) 30:S274-280. doi: 10.1097/00003246-200205001-00017

81. de Giorgio-Miller A, Bottoms S, Laurent G, Carmeliet P, Herrick S. Fibrininduced skin fibrosis in mice deficient in tissue plasminogen activator. Am J Pathol. (2005) 167:721-32. doi: 10.1016/S0002-9440(10)62046-9

82. Romer J, Bugge TH, Pyke C, Lund LR, Flick MJ, Degen JL, et al. Impaired wound healing in mice with a disrupted plasminogen gene. Nat Med. (1996) 2:287-92. doi: 10.1038/nm0396-287

83. Ma YJ, Doni A, Hummelshoj T, Honore C, Bastone A, Mantovani A, et al. Synergy between ficolin-2 and pentraxin 3 boosts innate immune recognition and complement deposition. J Biol Chem. (2009) 284:28263-75. doi: 10.1074/jbc.M109.009225

84. Ma YJ, Doni A, Romani L, Jurgensen HJ, Behrendt N, Mantovani A, et al. Ficolin-1-PTX3 complex formation promotes clearance of altered self-cells and modulates IL-8 production. J Immunol. (2013) 191:1324-33. doi: 10.4049/jimmunol.1300382

85. Schneider LA, Korber A, Grabbe S, Dissemond J. Influence of $\mathrm{pH}$ on woundhealing: a new perspective for wound-therapy? Arch Dermatol Res. (2007) 298:413-20. doi: 10.1007/s00403-006-0713-x

86. Mangel WF, Lin BH, Ramakrishnan V. Characterization of an extremely large, ligand-induced conformational change in plasminogen. Science. (1990) 248:69-73. doi: 10.1126/science. 2108500

87. Castellino FJ, Ploplis VA. Structure and function of the plasminogen/plasmin system. Thromb Haemost. (2005) 93:647-54. doi: 10.1160/TH0412-0842

88. Law RH, Caradoc-Davies T, Cowieson N, Horvath AJ, Quek AJ, Encarnacao JA, et al. The X-ray crystal structure of full-length human plasminogen. Cell Rep. (2012) 1:185-90. doi: 10.1016/j.celrep.2012.02.012

89. Ploplis VA, Carmeliet P, Vazirzadeh S, Van Vlaenderen I, Moons L, Plow EF, et al. Effects of disruption of the plasminogen gene on thrombosis, growth, and health in mice. Circulation. (1995) 92:2585-93. doi: 10.1161/01.CIR.92.9.2585

90. Hamilton JA. Stimulation of macrophage prostaglandin and neutral protease production by phorbol esters as a model for the induction of vascular changes associated with tumor promotion. Cancer Res. (1980) 40:2273-80.

91. Ku CS, Fiedel BA. Modulation of fibrin clot formation by human serum amyloid P component (SAP) and heparin. J Exp Med. (1983) 158:767-80. doi: $10.1084 /$ jem.158.3.767
92. Vandendries ER, Furie BC, Furie B. Role of P-selectin and PSGL1 in coagulation and thrombosis. Thromb Haemost. (2004) 92:459-66. doi: 10.1160/TH04-05-0306

93. Napoleone E, di Santo A, Peri G, Mantovani A, de Gaetano G, Donati $\mathrm{MB}$, et al. The long pentraxin PTX3 up-regulates tissue factor in activated monocytes: another link between inflammation and clotting activation. $J$ Leukoc Biol. (2004) 76:203-9. doi: 10.1189/jlb.1003528

94. Camozzi M, Zacchigna S, Rusnati M, Coltrini D, Ramirez-Correa G, Bottazzi B, et al. Pentraxin 3 inhibits fibroblast growth factor 2dependent activation of smooth muscle cells in vitro and neointima formation in vivo. Arterioscler Thromb Vasc Biol. (2005) 25:1837-42. doi: 10.1161/01.ATV.0000177807.54959.7d

95. Norata GD, Marchesi P, Pulakazhi Venu VK, Pasqualini F, Anselmo A, Moalli F, et al. Deficiency of the long pentraxin PTX3 promotes vascular inflammation and atherosclerosis. Circulation. (2009) 120:699-708. doi: 10.1161/CIRCULATIONAHA.108.806547

96. Sellheyer K, Krahl D. Skin mesenchymal stem cells: prospects for clinical dermatology. J Am Acad Dermatol. (2010) 63:859-65. doi: 10.1016/j.jaad.2009.09.022

97. Bey E, Prat M, Duhamel P, Benderitter M, Brachet M, Trompier F, et al. Emerging therapy for improving wound repair of severe radiation burns using local bone marrow-derived stem cell administrations. Wound Repair Regen. (2010) 18:50-8. doi: 10.1111/j.1524-475X.2009.00562.x

98. Ciccocioppo R, Bernardo ME, Sgarella A, Maccario R, Avanzini MA, Ubezio C, et al. Autologous bone marrow-derived mesenchymal stromal cells in the treatment of fistulising Crohn's disease. Gut. (2011) 60:788-98. doi: 10.1136/gut.2010.214841

99. Matthay MA, Ware LB, Zimmerman GA. The acute respiratory distress syndrome. J Clin Invest. (2012) 122:2731-40. doi: 10.1172/JCI60331

100. Long F. Building strong bones: molecular regulation of the osteoblast lineage. Nat Rev Mol Cell Biol. (2011) 13:27-38. doi: 10.1038/nrm3254

101. O'Keefe RJ. Fibrinolysis as a target to enhance fracture healing. N Engl J Med. (2015) 373:1776-8. doi: 10.1056/NEJMcibr1510090

102. Yuasa M, Mignemi NA, Nyman JS, Duvall CL, Schwartz HS, Okawa A, et al. Fibrinolysis is essential for fracture repair and prevention of heterotopic ossification. J Clin Invest. (2015) 125:3117-31. doi: 10.1172/JCI80313

103. Mantovani A, Allavena P, Sica A, Balkwill F. Cancer-related inflammation. Nature. (2008) 454:436-44. doi: 10.1038/nature07205

104. Markiewski MM, DeAngelis RA, Benencia F, Ricklin-Lichtsteiner SK, Koutoulaki A, Gerard C, et al. Modulation of the antitumor immune response by complement. Nat Immunol. (2008) 9:1225-35. doi: 10.1038/ni.1655

105. Ning C, Li YY, Wang Y, Han GC, Wang RX, Xiao H, et al. Complement activation promotes colitis-associated carcinogenesis through activating intestinal IL-1beta/IL-17A axis. Mucosal Immunol. (2015) 8:1275-84. doi: $10.1038 / \mathrm{mi} .2015 .18$

106. Guglietta S, Rescigno M. Hypercoagulation and complement: connected players in tumor development and metastases. Semin Immunol. (2016) 28:578-86. doi: 10.1016/j.smim.2016.10.011

107. Medler TR, Murugan D, Horton W, Kumar S, Cotechini T, Forsyth $\mathrm{AM}$, et al. Complement C5a fosters squamous carcinogenesis and limits $\mathrm{T}$ cell response to chemotherapy. Cancer Cell. (2018) 34:561-578.e566. doi: 10.1016/j.ccell.2018.09.003

108. Ronca R, Alessi P, Coltrini D, Salle ED, Giacomini A, Leali D, et al. Long Pentraxin-3 As An epithelial-stromal fibroblast growth factortargeting inhibitor in prostate cancer. J Pathol. (2013) 230:228-38. doi: $10.1002 /$ path.4181

109. Ronca R, Giacomini A, Di Salle E, Coltrini D, Pagano K, Ragona L, et al. Long-Pentraxin 3 derivative as a small-molecule FGF trap for cancer therapy. Cancer Cell. (2015) 28:225-39. doi: 10.1016/j.ccell.2015.07.002

110. Rodrigues PF, Matarazzo S, Maccarinelli F, Foglio E, Giacomini A, Silva Nunes JP, et al. Long Pentraxin 3-mediated fibroblast growth factor trapping impairs fibrosarcoma growth. Front Oncol. (2018) 8:472. doi: 10.3389/fonc.2018.00472

111. Wang JX, He YL, Zhu ST, Yang S, Zhang ST. Aberrant methylation of the 3q25 tumor suppressor gene PTX3 in human esophageal squamous cell carcinoma. World J Gastroenterol. (2011) 17:4225-30. doi: 10.3748/wjg.v17.i37.4225 
112. Tsuji S, Midorikawa Y, Seki M, Takayama T, Sugiyama Y, Aburatani H. Network-based analysis for identification of candidate genes for colorectal cancer progression. Biochem Biophys Res Commun. (2016) 476:534-40. doi: 10.1016/j.bbrc.2016.05.158

113. Choi B, Lee EJ, Park YS, Kim SM, Kim EY, Song Y, et al. Pentraxin3 silencing suppresses gastric cancer-related inflammation by inhibiting chemotactic migration of macrophages. Anticancer Res. (2015) 35:2663-8.

114. Ying TH, Lee CH, Chiou HL, Yang SF, Lin CL, Hung CH, et al. Knockdown of Pentraxin 3 suppresses tumorigenicity and metastasis of human cervical cancer cells. Sci Rep. (2016) 6:29385. doi: 10.1038/srep29385

115. Thomas C, Henry W, Cuiffo BG, Collmann AY, Marangoni E, Benhamo $\mathrm{V}$, et al. Pentraxin-3 is a PI3K signaling target that promotes stem celllike traits in basal-like breast cancers. Sci Signal. (2017) 10:eaah4674. doi: 10.1126/scisignal.aah4674

116. Tothill RW, Tinker AV, George J, Brown R, Fox SB, Lade S, et al. Novel molecular subtypes of serous and endometrioid ovarian cancer linked to clinical outcome. Clin Cancer Res. (2008) 14:5198-208. doi: 10.1158/1078-0432.CCR-08-0196

117. Choi B, Lee EJ, Song DH, Yoon SC, Chung YH, Jang Y, et al. Elevated Pentraxin 3 in bone metastatic breast cancer is correlated with osteolytic function. Oncotarget. (2014) 5:481-92. doi: 10.18632/oncotarget.1664

118. Chen WY, Wu F, You ZY, Zhang ZM, Guo YL, Zhong LX. Analyzing the differentially expressed genes and pathway cross-talk in aggressive breast cancer. J Obstet Gynaecol Res. (2015) 41:132-40. doi: 10.1111/jog.12495

119. Player A, Abraham N, Burrell K, Bengone IO, Harris A, Nunez L, et al. Identification of candidate genes associated with triple negative breast cancer. Genes Cancer. (2017) 8:659-72. doi: 10.18632/genesandcancer.147

120. Espinal-Enriquez J, Munoz-Montero S, Imaz-Rosshandler I, Huerta-Verde A, Mejia C, Hernandez-Lemus E. Genome-wide expression analysis suggests a crucial role of dysregulation of matrix metalloproteinases pathway in undifferentiated thyroid carcinoma. BMC Genomics. (2015) 16:207. doi: 10.1186/s12864-015-1372-0

121. Willeke F, Assad A, Findeisen P, Schromm E, Grobholz R, von Gerstenbergk B, et al. Overexpression of a member of the pentraxin family (PTX3) in human soft tissue liposarcoma. Eur J Cancer. (2006) 42:2639-46. doi: 10.1016/j.ejca.2006.05.035

122. Ravenna L, Sale P, Di Vito M, Russo A, Salvatori L, Tafani M, et al. Upregulation of the inflammatory-reparative phenotype in human prostate carcinoma. Prostate. (2009) 69:1245-55. doi: 10.1002/pros.20966

123. Tafani M, Di Vito M, Frati A, Pellegrini L, De Santis E, Sette G, et al. Proinflammatory gene expression in solid glioblastoma microenvironment and in hypoxic stem cells from human glioblastoma. J Neuroinflamm. (2011) 8:32. doi: 10.1186/1742-2094-8-32

124. Barbui T, Carobbio A, Finazzi G, Vannucchi AM, Barosi G, Antonioli E, et al. Inflammation and thrombosis in essential thrombocythemia and polycythemia vera: different role of C-reactive protein and pentraxin 3 . Haematologica. (2011) 96:315-8. doi: 10.3324/haematol.2010.031070

125. Germano G, Frapolli R, Simone M, Tavecchio M, Erba E, Pesce S, et al. Antitumor and anti-inflammatory effects of trabectedin on human myxoid liposarcoma cells. Cancer Res. (2010) 70:2235-44. doi: 10.1158/0008-5472.CAN-09-2335

126. Planque C, Kulasingam V, Smith CR, Reckamp K, Goodglick L, Diamandis EP. Identification of five candidate lung cancer biomarkers by proteomics analysis of conditioned media of four lung cancer cell lines. Mol Cell Proteomics. (2009) 8:2746-58. doi: 10.1074/mcp.M900134-MCP200

127. Diamandis EP, Goodglick L, Planque C, Thornquist MD. Pentraxin-3 is a novel biomarker of lung carcinoma. Clin Cancer Res. (2011) 17:2395-9. doi: 10.1158/1078-0432.CCR-10-3024

128. Infante $\mathrm{M}$, Allavena $\mathrm{P}$, Garlanda C, Nebuloni M, Morenghi E, Rahal D, et al. Prognostic and diagnostic potential of local and circulating levels of pentraxin 3 in lung cancer patients. Int J Cancer. (2016) 138:983-91. doi: $10.1002 /$ ijc. 29822
129. Kondo S, Ueno H, Hosoi H, Hashimoto J, Morizane C, Koizumi F, et al. Clinical impact of pentraxin family expression on prognosis of pancreatic carcinoma. Br J Cancer. (2013) 109:739-46. doi: 10.1038/bjc.2013.348

130. Locatelli M, Ferrero S, Martinelli Boneschi F, Boiocchi L, Zavanone M, Maria Gaini S, et al. The long pentraxin PTX3 as a correlate of cancer-related inflammation and prognosis of malignancy in gliomas. J Neuroimmunol. (2013) 260:99-106. doi: 10.1016/j.jneuroim.2013.04.009

131. Carmo RF, Aroucha D, Vasconcelos LR, Pereira LM, Moura P, Cavalcanti MS. Genetic variation in PTX3 and plasma levels associated with hepatocellular carcinoma in patients with HCV. J Viral Hepat. (2016) 23:116-22. doi: $10.1111 /$ jvh. 12472

132. Berg J, Halvorsen AR, Bengtson MB, Tasken KA, Maelandsmo GM, Yndestad A, et al. Levels and prognostic impact of circulating markers of inflammation, endothelial activation and extracellular matrix remodelling in patients with lung cancer and chronic obstructive pulmonary disease. BMC Cancer. (2018) 18:739. doi: 10.1186/s12885-0184659-0

133. Liu C, Yao Y, Wang W. Pentraxin-3 as a prognostic marker in patients with small-cell lung cancer. Med Oncol. (2014) 31:207. doi: 10.1007/s12032-014-0207-1

134. Stallone G, Cormio L, Netti GS, Infante B, Selvaggio O, Fino GD, et al. Pentraxin 3: a novel biomarker for predicting progression from prostatic inflammation to prostate cancer. Cancer Res. (2014) 74:4230-8. doi: 10.1158/0008-5472.CAN-14-0369

135. Zhang J, Wang TY, Niu XC. Increased plasma levels of Pentraxin 3 are associated with poor prognosis of colorectal carcinoma patients. Tohoku J Exp Med. (2016) 240:39-46. doi: 10.1620/tjem.240.39

136. Liu B, Zhao Y, Guo L. Increased serum pentraxin-3 level predicts poor prognosis in patients with colorectal cancer after curative surgery, a cohort study. Medicine. (2018) 97:e11780. doi: 10.1097/MD.0000000000011780

137. Di Caro G, Carvello M, Pesce S, Erreni M, Marchesi F, Todoric $\mathrm{J}$, et al. Circulating inflammatory mediators as potential prognostic markers of human colorectal cancer. PLoS ONE. (2016) 11:e0148186. doi: 10.1371/journal.pone.0148186

138. Dvorak HF. Tumors: wounds that do not heal. Similarities between tumor stroma generation and wound healing. N Engl J Med. (1986) 315:1650-9. doi: 10.1056/NEJM198612253152606

139. Clark RA. Fibrin and wound healing. Ann N Y Acad Sci. (2001) 936:355-67. doi: 10.1111/j.1749-6632.2001.tb03522.x

140. Ortega S, Ittmann M, Tsang SH, Ehrlich M, Basilico C. Neuronal defects and delayed wound healing in mice lacking fibroblast growth factor 2. Proc Nat Acad Sci USA. (1998) 95:5672-7. doi: 10.1073/pnas.95.10.5672

141. Rafail S, Kourtzelis I, Foukas PG, Markiewski MM, DeAngelis RA, Guariento $\mathrm{M}$, et al. Complement deficiency promotes cutaneous wound healing in mice. J Immunol. (2015) 194:1285-91. doi: 10.4049/jimmunol.1402354

142. Dvorak HF. Tumors: wounds that do not heal-redux. Cancer Immunol Res. (2015) 3:1-11. doi: 10.1158/2326-6066.CIR-14-0209

143. Reis ES, Mastellos DC, Ricklin D, Mantovani A, Lambris JD. Complement in cancer: untangling an intricate relationship. Nat Rev Immunol. (2018) 18:5-18. doi: 10.1038/nri.2017.97

Conflict of Interest Statement: The authors declare that the research was conducted in the absence of any commercial or financial relationships that could be construed as a potential conflict of interest.

Copyright (c) 2019 Doni, Stravalaci, Inforzato, Magrini, Mantovani, Garlanda and Bottazzi. This is an open-access article distributed under the terms of the Creative Commons Attribution License (CC BY). The use, distribution or reproduction in other forums is permitted, provided the original author(s) and the copyright owner(s) are credited and that the original publication in this journal is cited, in accordance with accepted academic practice. No use, distribution or reproduction is permitted which does not comply with these terms. 